\title{
Wear and Friction Properties of Electrodeposited Ni-Based Coatings Subject to Nano-enhanced Lubricant and Composite Coating
}

\author{
Rizwan Bajwa $^{1} \cdot$ Zulfiqar Khan $^{1} \cdot$ H. Nazir $^{1} \cdot$ Vivek Chacko $^{1} \cdot$ Adil Saeed $^{1}$
}

Received: 10 April 2016/Revised: 13 June 2016/Published online: 5 August 2016

(C) The Chinese Society for Metals and Springer-Verlag Berlin Heidelberg 2016

\begin{abstract}
This paper presents research findings on the tribological performance of electrodeposited coatings subject to nano-lubricants with the addition of nano- $\mathrm{Al}_{2} \mathrm{O}_{3}$ and graphene and $\mathrm{Ni} / \mathrm{nano}^{-} \mathrm{Al}_{2} \mathrm{O}_{3}$ composite coatings. Electrodeposited coatings were produced by using a pulse electrodeposition method. Tribological experiments were conducted by using a linear reciprocating ball on flat sliding tribometer. Experimental results confirmed that the wear and friction resistance properties were significantly enhanced by doping of nano-effects in the lubricating oil and composite coating. The addition of $\mathrm{Al}_{2} \mathrm{O}_{3}$ nanoparticles in the lubricating oil showed the best tribological properties, followed by $\mathrm{Ni}-\mathrm{Al}_{2} \mathrm{O}_{3}$ composite coatings and nano-oil with graphene. The surface morphology and microstructure of electrodeposited coatings were examined by scanning electron microscopy, energy-dispersive spectroscopy and X-ray diffraction. The wear mechanisms of these coatings subjected to tribological testing were investigated by post-test surface analyses. This research provides a novel approach to design durable nano-coatings for tribological applications in various industries such as automotive, aerospace, locomotive and renewable energy technologies.
\end{abstract}

KEY WORDS: Tribology; Nanoparticles; Graphene; Nano-additives; Nano-coatings

\section{Introduction}

This paper enables researchers to fully understand the advantages of two distinct approaches of nano-additives within lubricants and nano-coatings, to solve complex tribological issues in terms of design for durability and reliability. Optimisation of surfaces in contact and in relative motion is needed to enhance their tribological performance. This research is focus on enhancing the tribological performance of contact surfaces through nano-composite coatings and nano-additives in lubrication. Almost one-

Available online at http://link.springer.com/journal/40195.

Rizwan Bajwa

rbajwa@bournemouth.ac.uk

1 NanoCorr, Energy and Modelling Research Group, Bournemouth University, Poole, UK third of the energy losses in mechanically interacting systems or components are attributed to friction or wear behaviour. For a long time, oil lubricants or greases have been used to reduce these frictional forces and wear asperities between two interacting surfaces. In recent years, nanoparticles have been widely studied in various applications due to their unique wear, friction and corrosion resistant properties. Nanoparticles are used both as an additive in the lubricant oil and as a metal matrix nanocomposite (MMC) materials. The term nano-additive is commonly used for nanoparticles when they are used as an additive to conventional lubricants. Many studies have reported an effective role of nano-additives in lubricants in terms of the improvement of anti-friction and anti-wear properties of materials [1-3]. These nano-additives are made up of nano-sized metals [4], metal-oxides [5] and diamond nanoparticles [6]. The optimum fraction of nanoadditives in lubricants is an important factor. Several studies have been conducted to investigate the optimised 
percentage of nanoparticles in lubricants to achieve the best tribological properties [7-9]. Their results concluded that the optimised concentration of nano-sized particles in lubricants is always $<1 \%$. This is because of the higher concentration can lead to surface damage due to extensive wear and high frictional heat.

On the other hand, the use of nanoparticles in composite coatings is also widely investigated in the last decades. Likewise, the composite coatings incorporating a variety of nanoparticles made up of nano-sized alumina oxide [10-12], zirconium oxide [13-15], titanium oxide [16], iron (III) oxide $\mathrm{Fe}_{2} \mathrm{O}_{3}$ [17], cerium oxide $\mathrm{CeO}_{2}$ [18] and carbides such as silicon carbide [19, 20] and tungsten carbide WC [21] have enhanced anti-wear, anti-friction, anti-corrosion and mechanical properties. In addition, in composite coatings/materials the concentration of reinforcement content of nanoparticles is an important factor to obtain optimum tribological properties. Recently, Gül et al. [22] investigated the influences of particle concentration on the tribological properties of nickel composite incorporating silicon carbide particles. It was found that $20 \mathrm{~g} \mathrm{~L}^{-1}$ concentration of immersed particles in the electrolyte demonstrated excellent anti-wear properties of co-deposited coatings. BeltowskaLehman et al. [23] examined the influence of ultrasonic treatment during the deposition process of nickel-zirconia nano-composite coating on their microstructural and functional properties. It was established that the lower ultrasonic treatment demonstrated excellent nanoparticles distribution in the matrix, and consequently, enhanced mechanical properties were achieved.

In recent years, a few studies have been reported on the use of graphene as an additive in the lubricating oil [24-26]. It was found that the anti-wear and anti-friction properties were improved significantly with the addition of graphene in the lubricant. Researchers investigated the effects of varying content ratios of graphene in lubricants on their tribological behaviour [26]. It was found that the average friction coefficient was reduced by $24 \%$ with the addition of $0.5 \mathrm{vol} \%$ of graphene. Lin et al. [25] studied the tribological properties of chemically modified graphene platelets in stearic and oleic acids. They concluded that the optimal value of $0.07 \mathrm{wt} \%$ of modified graphene platelets can significantly enhance the anti-wear and anti-friction properties than that of raw oil.

The influence of micro- and nano-sized alumina particles on the corrosion resistance of Ni-based coatings was investigated by Zhou et al. [27]. It was found that the reinforcement of nano-alumina presented better corrosion resistance than that of microalumina particles in nickel composite. This is because of better particle distributions and relatively refined compact microstructure of nanoalumina composite coatings. Previously, the effect of chemical solution concentration on the tribological performance of pure nickel and nickel-alumina composite coatings was investigated [12]. It was found that the ionic strength of electrolyte has significant influence on the tribological and mechanical properties of electrodeposited coatings. The effect of electrodeposition methods and incorporating various nanoparticles such as $\mathrm{Al}_{2} \mathrm{O}_{3}, \mathrm{SiC}$ and $\mathrm{ZrO}_{2}$ were studied by Borkar and Harimkar [13]. It was concluded that pulse current can present better tribological properties of electrodeposited composite coatings. Furthermore, the nickel composite of alumina nanoparticle exhibits better mechanical and anti-wear properties than $\mathrm{Ni}-\mathrm{SiC}$ and $\mathrm{Ni}-\mathrm{ZrO}_{2}$ composites.

Tribological performance of various nano-lubricants and nano-composite coatings has been investigated extensively as reported above. Nevertheless, it has been left ambiguous that whether nano-lubricant or nano-composite coatings approach provides a more favourable solution to ever growing tribological operational challenges. Therefore, tribological properties of nano-dispersed lubricants and nano-composite are experimentally evaluated and comparative results are presented here. X-ray diffraction (XRD) results are extended from the previous reported work [15] in which the tribological performance of various nano-composite was investigated. This research is a continuation of existing work in terms of enhancing tribological and anti-corrosive properties in harsh environment [28-41].

\section{Experimental}

\subsection{Preparation and Characterisation of Coated Samples}

Pure $\mathrm{Ni}$ and Ni-alumina nano-composite coatings ( $\sim 10 \mu \mathrm{m}$ in thickness) were produced by electrodeposition method. Pulse current condition was controlled by using a MicroStar Pulse Interface connected to Dynatronix pulse power supply. The pulse current conditions were kept persistent as current density $3 \mathrm{~A} / \mathrm{dm}^{2}$, pulse on/off time (20-80 ms) and a duty cycle of $20 \%$. An optimised Watt's bath chemical composition was used for deposition process based on previous findings [12]. For the development of nano-enhanced composite coating, alumina nanoparticles (40-50 nm; supplied by Lo-Li-Tech) were added into an electroplating bath under continuous magnetic stirring process. Moreover, to ensure better suspension of particles, the chemical solution was ultrasonically stirred during the deposition process. A nickel sheet with high purity was used as anode and a steel rectangular plate of dimensions $30 \mathrm{~mm} \times 10 \mathrm{~mm} \times 3 \mathrm{~mm}$ to be coated on both sides as a cathode. Standard surface conditioning was deployed before coating development process. Flat plate specimen, 
to be coated with a surface area of $0.09 \mathrm{dm}^{2}$, was mechanically polished to an average roughness of $0.05 \mu \mathrm{m}$ and ultrasonically conditioned with acetone.

Surface morphology of electrodeposited samples was studied by using a scanning electron microscope (SEM, JSM-6010, JEOL). The elements content analysis was conducted by using an energy-dispersive X-ray spectroscope (EDS). X-ray diffraction (XRD) analysis (D8 Advance, Bruker) was conducted in $2 \theta$ range of $20^{\circ}-100^{\circ}$ and with a step increment of $0.02^{\circ}$.

\subsection{Preparation of Nano-lubricants}

Nano-enhanced lubricants were fabricated by using a commercial oil SAE10W40 with the addition of $0.1 \mathrm{wt} \%$ $\mathrm{Al}_{2} \mathrm{O}_{3}$ nanoparticles and graphene, respectively. Nanoparticles and graphene were added into oil under continuous sonication process to achieve better suspension and then cooled down to room temperature. Figure 1 displays a visual appearance of pure oil and nano-oils with uniformly dispersed nanoparticles and graphene platelets. A clear yellow colour was apparent of pure oil as shown in Fig. 1a. However, nano-oils displayed darker yellow and black colour due to dispersed nanoparticle and graphene platelets, respectively, as shown in Fig. 1b, c.

\subsection{Tribological Performance Testing}

Tribological behaviour tests were conducted in accordance with ASTM G133 wear test principle by using a linearly reciprocating sliding wear/friction tribometer. A schematic diagram of reciprocating sliding contact set-up is shown in Fig. 2. Briefly describing the tribometer consisted of lower fixed electroplated plate $(30 \mathrm{~mm} \times 10 \mathrm{~mm} \times 3 \mathrm{~mm})$ and

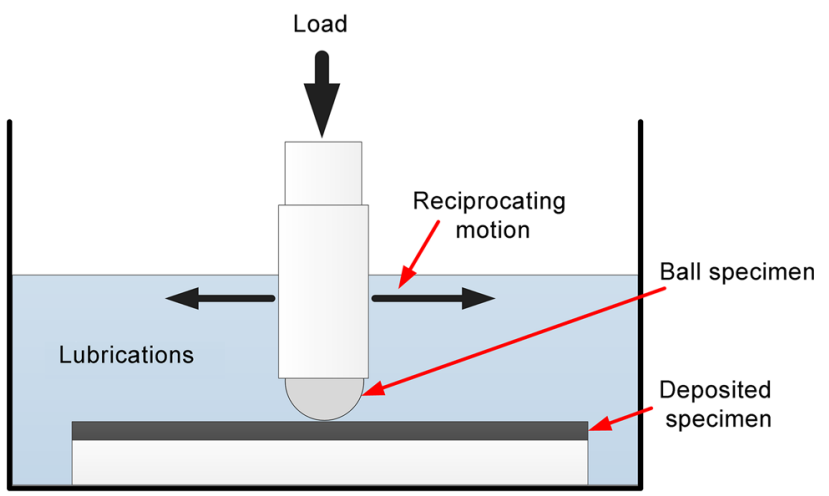

Fig. 2 Schematic diagram of reciprocating sliding contact testing

upper 100Cr6 steel ball (H: 740HV10, E: 210GPa and v: 0.3 ) of a $9.525 \mathrm{~mm}$ diameter. All tests were performed under a constant load of $15 \mathrm{~N}$, reciprocating frequency of $10 \mathrm{~Hz}$ and stroke length of $5 \mathrm{~mm}$. These testing conditions were selected to maintain a boundary lubrication regime. Tribological performance data had been collected on coated specimen before these coatings were completely failed. Four different types of tribological tests were conducted as listed in Table 1. Each tribological test was repeated three times to ensure the repeatability and to achieve the minimum data scattering.

Post-test surface analyses of worn tracks during wear experiments were performed to investigate the wear mechanism and elemental contents by SEM and EDS, respectively. Three-dimensional white light interferometer (ZYGO) was used to measure the wear volume of the worn surfaces of the coated specimens. Wear volume was calculated as $V=A L$, where $A$ is the cross-sectional area of the worn scar in $\mathrm{mm}^{2}$, and $L$ is the length of the worn scar in $\mathrm{mm}$. The specific wear rate $\left(\mathrm{mm}^{3} / \mathrm{Nm}\right)$ was determined

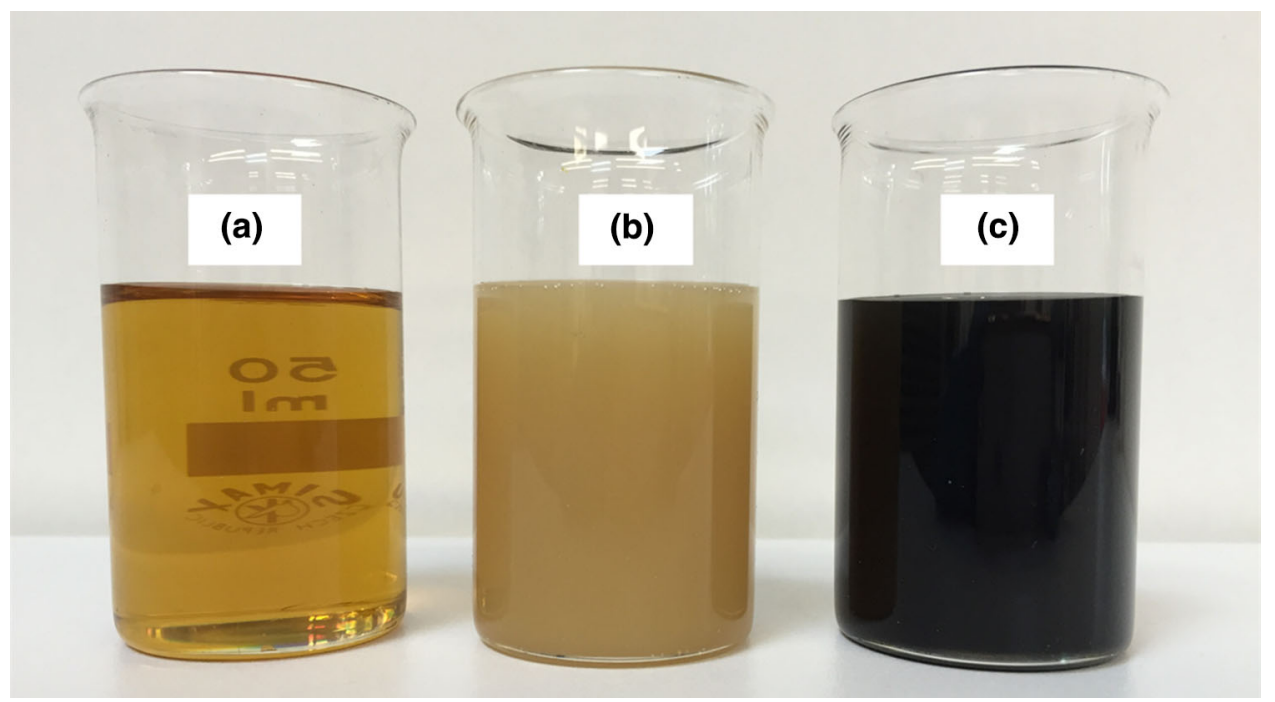

Fig. 1 Visual appearance of lubricants after combined ultrasonic and mechanical agitation: a pure oil, b oil + nano- $\mathrm{Al}_{2} \mathrm{O}_{3}, \mathbf{c}$ oil + graphene 
Table 1 List of tribopairs and corresponding lubricating oil conditions

\begin{tabular}{lll}
\hline Test type & Tribopairs & Lubricants \\
\hline 1 & Steel ball/pure Ni coatings & Pure oil \\
2 & Steel ball/Ni- $\mathrm{Al}_{2} \mathrm{O}_{3}$ coatings & Pure oil \\
3 & Steel ball/pure Ni coatings & Nano-oil with nano-alumina \\
4 & Steel ball/pure Ni coatings & Nano-oil with graphene \\
\hline
\end{tabular}
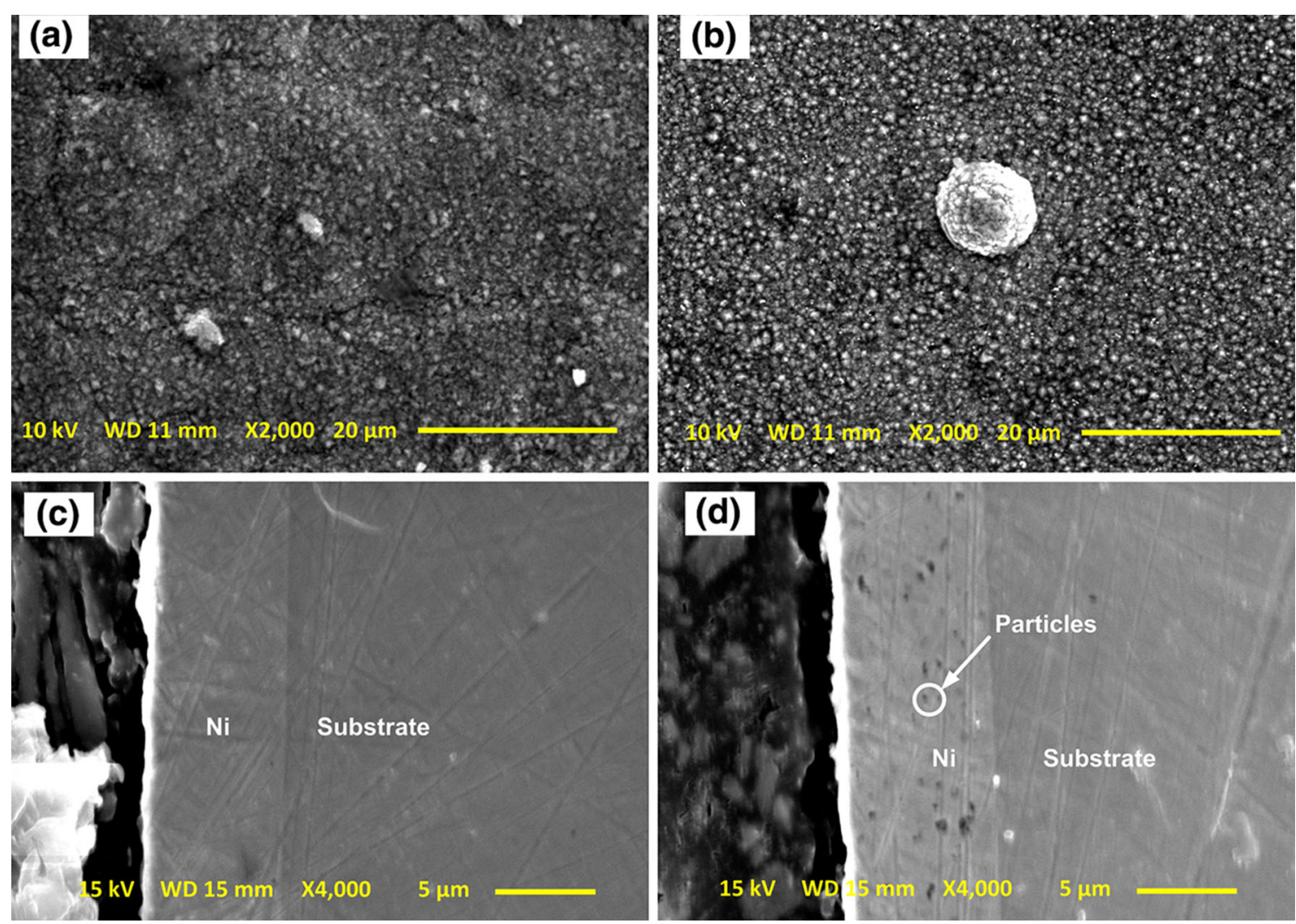

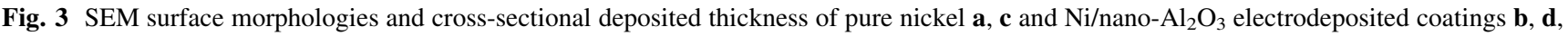
respectively

as a function of the wear volume $V\left(\mathrm{~mm}^{3}\right)$ divided by the applied load $(N)$ multiplied by sliding distance $S(\mathrm{~m})$ [15]. The tangential friction force at the contact interface was recorded continuously by using a piezoelectric transducer. The coefficient of friction was then calculated from measured friction force dividing by normal applied load.

\section{Results and Discussion}

\subsection{SEM and XRD Surface Morphology of Electrodeposited Samples}

Surface morphologies of electrodeposited pure nickel and nickel composite of nano-sized alumina coatings are shown in Fig. 3a, b, respectively. The effect of reinforced $\mathrm{Al}_{2} \mathrm{O}_{3}$ nanoparticle on microstructure morphology of electroplated coating is evident from changes in grain structure of $\mathrm{Ni}$ coatings. Typical pyramidal and globular-shaped microstructure of composite coating is shown in Fig. 3b. In comparison with pure $\mathrm{Ni}$, the crystallite grains of composite coating exhibit more compact morphology with clear grain edges. These surface morphologies of electrodeposited $\mathrm{Ni}$ and $\mathrm{Ni}$-alumina composites are consistent with the previous observations $[42,43]$. The reduced grain sizes and compact morphology of composite coatings incorporating nanoparticles have been attributed to the cathodic polarisation as a result of nanoparticles adsorption at cathode specimen surface. The addition of nano-sized alumina in the nickel matrix leads to the formation of 

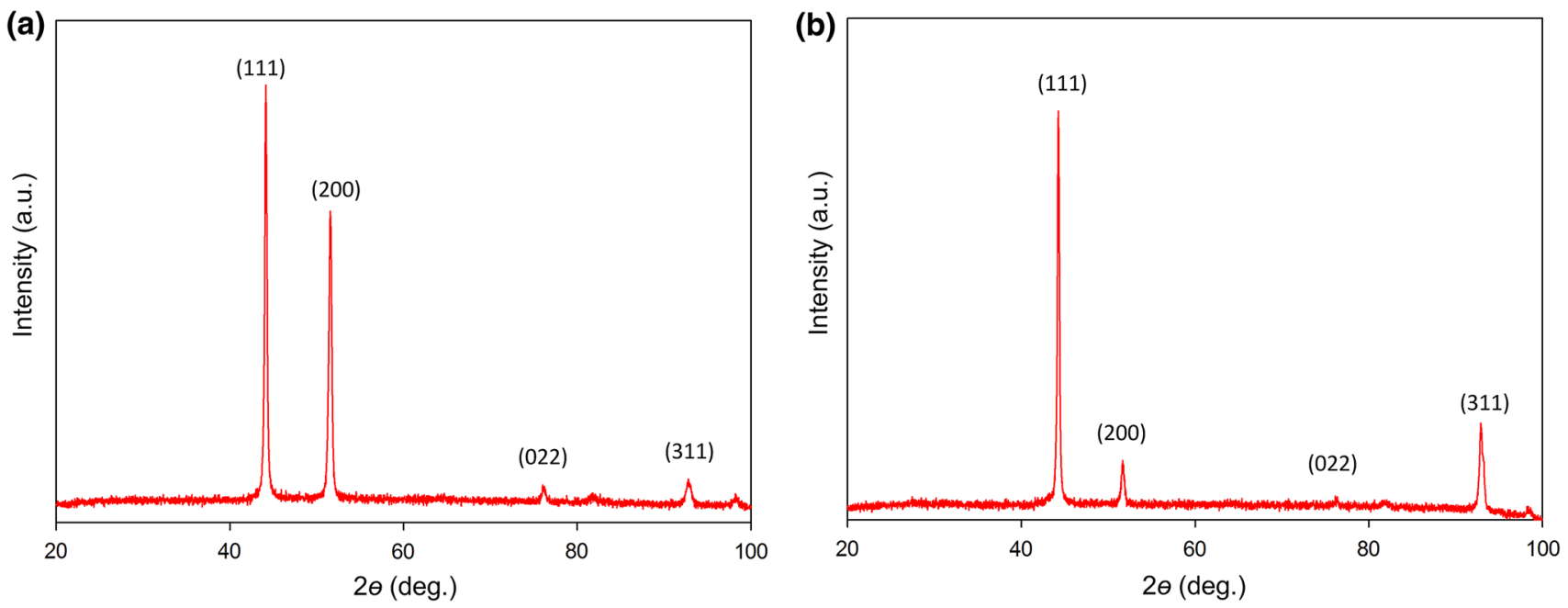

Fig. 4 XRD patterns of pure nickel $\mathbf{a}$ and $\mathrm{Ni} /$ nano- $-\mathrm{Al}_{2} \mathrm{O}_{3}$ electrodeposited coatings $\mathbf{b}$

agglomerated spherical particles on the surface of composite coatings as shown in Fig. 3b. This agglomerated morphology was also reported by Borkar and Harimkar [13] for $\mathrm{Ni}-\mathrm{Al}_{2} \mathrm{O}_{3}$ composite coatings which contributed to the higher surface roughness of resulted coatings. The distribution of incorporated nanoparticles in the co-deposited coatings and cross-sectional thickness of deposited coatings were observed by SEM and are shown in Fig. 3c, d. It is evident that coatings are crack-free and well adhered to the substrate and nanoparticles are homogeneously distributed in the nickel matrix.

Figure $4 \mathrm{a}, \mathrm{b}$ presents XRD results of pure $\mathrm{Ni}$ and $\mathrm{Ni}-$ alumina composite coatings. XRD patterns were categorised by the typical high intensity peaks of (111) and

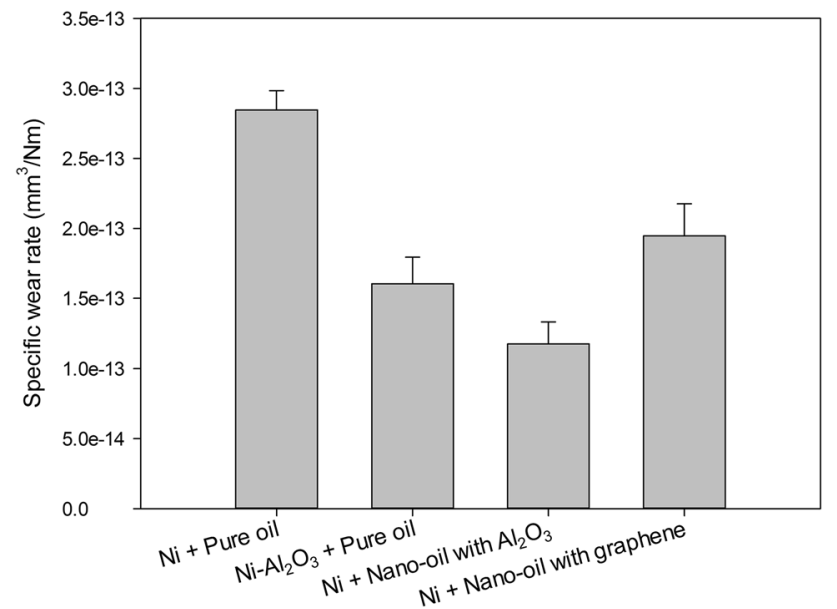

Fig. 5 Variation in specific wear rate post-tribotesting conditions of $\mathrm{Ni}$ coatings under pure oil, $\mathrm{Ni}-\mathrm{Al}_{2} \mathrm{O}_{3}$ under pure oil, $\mathrm{Ni}$ coatings under nano-oil with nano- $\mathrm{Al}_{2} \mathrm{O}_{3}$ and $\mathrm{Ni}$ coatings under nano-oil with graphene
(200) as reported previously by other researchers [44, 45] for Ni-based coatings. Reduction in crystallite size of the nickel-alumina composite is evident from low intensity peaks than pure Ni coatings intensity peaks. The corresponding peaks of nano-sized alumina particles were not possible to retrieve due to nano-sized and very low loaded content of particles in the nickel matrix.

\subsection{Anti-wear Characteristics}

In Fig. 5, the wear resistance results of electrodeposited coatings are compared when using nanoparticles as reinforced contents in nickel matrix and as an additive in the lubricating

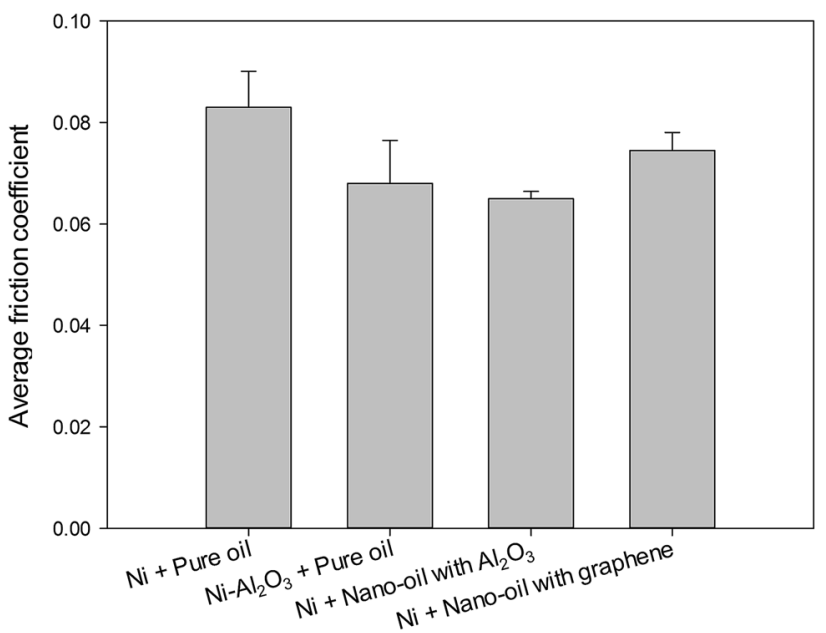

Fig. 6 Variation in average friction coefficient post-tribotesting conditions of $\mathrm{Ni}$ coatings under pure oil, $\mathrm{Ni}-\mathrm{Al}_{2} \mathrm{O}_{3}$ under pure oil, $\mathrm{Ni}$ coatings under nano-oil with nano- $\mathrm{Al}_{2} \mathrm{O}_{3}$ and $\mathrm{Ni}$ coatings under nano-oil with graphene 

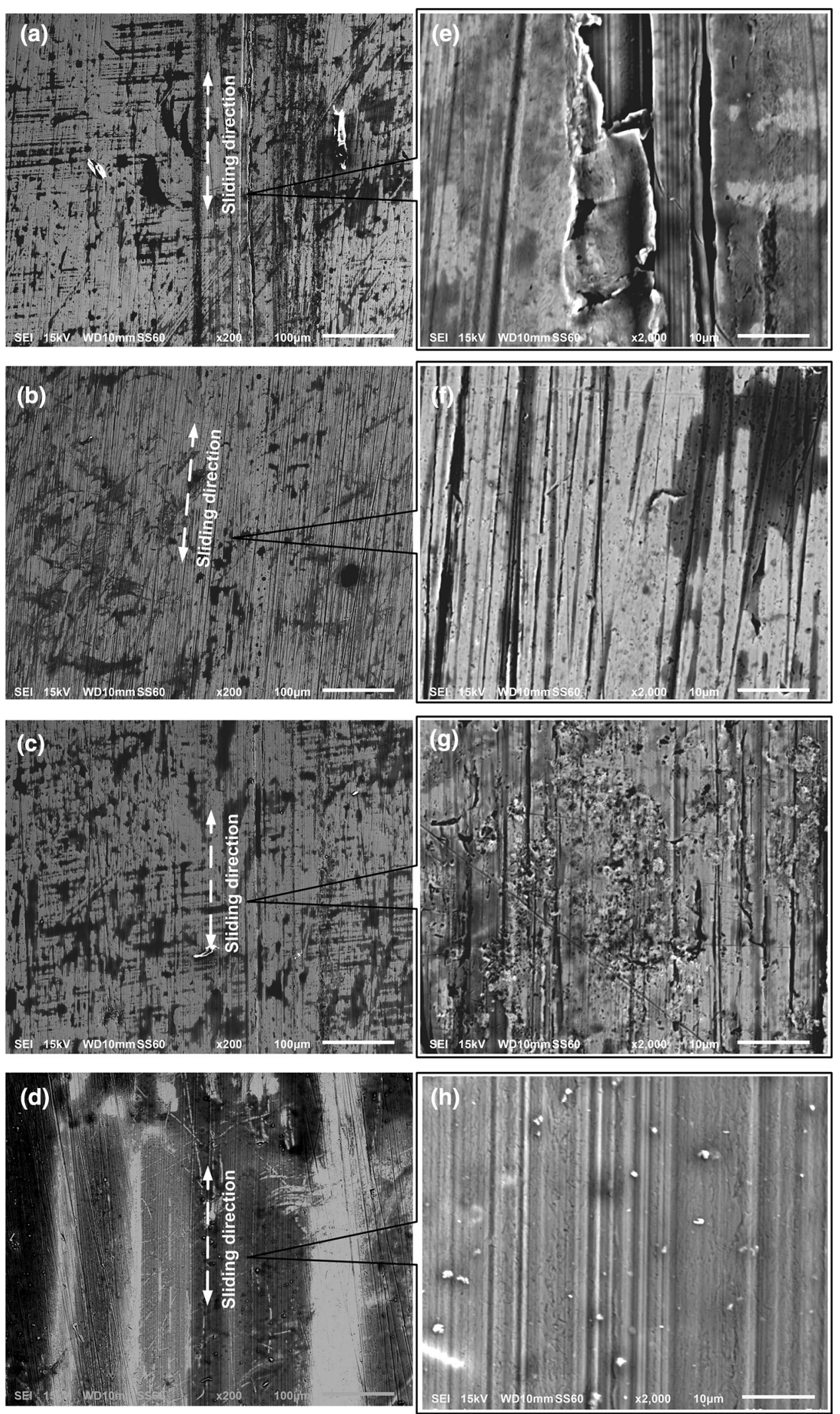

Fig. 7 SEM images with overall and magnified view of worn surface post-tribotesting conditions: $\mathbf{a}, \mathbf{e ~ N i}$ coatings under pure oil, $\mathbf{b}, \mathbf{f} \mathrm{Ni}_{-} \mathrm{Al}_{2} \mathrm{O}_{3}$ under pure oil, $\mathbf{c}, \mathbf{g}$ Ni coatings under nano-oil with nano- $\mathrm{Al}_{2} \mathrm{O}_{3}, \mathbf{d}, \mathbf{h}$ Ni coatings under nano-oil with graphene 
oil. By comparing with pure nickel coating under pure oil lubrication, nano-enhanced conditions (with the addition of nanoparticle in the matrix or oil) significantly enhanced antiwear properties. Wear rate is reduced by $58.59 \%$ with $0.1 \mathrm{wt} \%$ addition of nano-alumina nanoparticle in pure lubricating oil. On the other hand, the wear rate is reduced by $43.86 \%$ with reinforcement of $\mathrm{Al}_{2} \mathrm{O}_{3}$ nanoparticles in nickel matrix followed by nano-oil with the addition of graphene with reduction of about $30 \%$. Therefore, it is evident from Fig. 5 that the use of $\mathrm{Al}_{2} \mathrm{O}_{3}$ nanoparticle as an additive in the lubricating oil exhibits better wear resistance. This reduction in wear behaviour of electrodeposited coating with doping of nano-sized particles in both cases can be credited to three main reasons. First, the nanoparticles in lubricating oil or into the nickel matrix reduced the direct contact between two surfaces during sliding contact, and consequently the wear rate decreased [13]. Second, the self-repairing properties of nanoparticles contributed to the reduction in the abrasion mechanism [46]. The formation of a protective tribofilm with the presence of nanoparticles decreases the wear as confirmed by several researchers [47-49].

Similar wear rate results were observed in previous work [15] in which wear characteristic of pure nickel and $\mathrm{Ni}-\mathrm{Al}_{2} \mathrm{O}_{3}$ composite were studied subject to water-lubricated conditions. However, microploughing and microcutting wear mechanisms were observed on the coatings wear tracks. In addition to nano-effects, the reduced surface damage behaviour in this study may relate to higher viscosity lubricating oil.

\subsection{Friction Coefficient Characteristics}

Experimental results of average coefficient of friction during sliding ball on disc test are shown in Fig. 6. As shown in Fig. 6, the friction coefficient is lower in nano-enhanced composite coatings and nano-oil (with nano- $\mathrm{Al}_{2} \mathrm{O}_{3}$ or
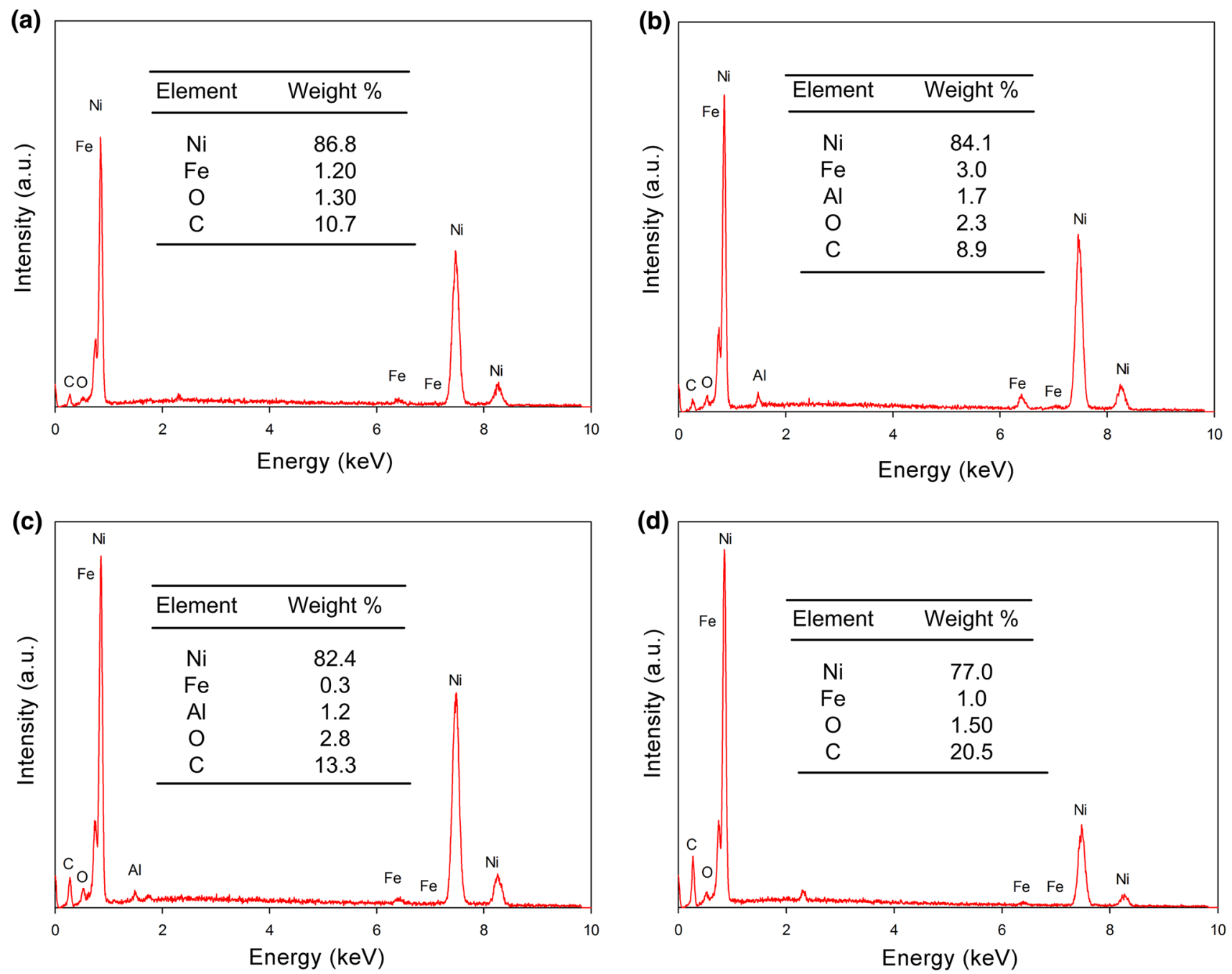

Fig. 8 EDS spectrum analysis of worn surface post-tribotesting conditions: a $\mathrm{Ni}$ coatings under pure oil, $\mathbf{b} \mathrm{Ni}-\mathrm{Al}_{2} \mathrm{O}_{3}$ under pure oil, $\mathbf{c} \mathrm{Ni}$ coatings under nano-oil with nano- $\mathrm{Al}_{2} \mathrm{O}_{3}$, d Ni coatings under nano-oil with graphene 
graphene) than that of the pure nickel coating under pure oil friction testing. Friction coefficient is reduced by $21.69 \%$ in nano-oil incorporating nano- $\mathrm{Al}_{2} \mathrm{O}_{3}$ particles followed by $\mathrm{Ni}-\mathrm{Al}_{2} \mathrm{O}_{3}$ composite coatings and nano-oil incorporating graphene with reduction of $18.07 \%$ and $9.64 \%$, respectively. This is because of load-bearing effect of the addition of reinforced nano-alumina nanoparticles in the composite and as an additive in the lubricating oil. This premise is also confirmed by other researchers about various nano-sized nanoparticles $[2,50]$.

In summary, it can be concluded that by using $0.1 \mathrm{wt} \%$ $\mathrm{Al}_{2} \mathrm{O}_{3}$ nano-sized particles as a nano-additive in the lubricating oil can produce better anti-friction and antiwear properties than if reinforced in the nickel matrix.

\subsection{Worn Surface Characteristics}

SEM and EDS were used to investigate worn surfaces. Figure 7 shows the overall and magnified view of worn tracks after the wear/friction tests with $\mathrm{Ni}$ coatings/pure oil, $\mathrm{Ni}-\mathrm{Al}_{2} \mathrm{O}_{3}$ /pure oil, $\mathrm{Ni}$ coatings/nano-oil with nano$\mathrm{Al}_{2} \mathrm{O}_{3}$ and $\mathrm{Ni}$ coatings/nano-oil with graphene. Figure 7a, e presents the worn wear track of pure Ni coating after testing with pure lubricating oil. From magnified view in Fig. 7e, severe surface wear can be seen where grooves and coating delamination take place, whereas the tribological tests conducted with nano-composite and that of nano-enhanced lubricant oil incorporating nano-alumina particles and graphene showed relatively much smooth worn surface without coating delamination, as shown in Fig. $7 \mathrm{~b}-\mathrm{d}, \mathrm{f}-\mathrm{h}$, respectively. Nano-lubricants with addition of nano-alumina particles exhibit relatively smoother worn surface. These observations also validate the wear rate results of the corresponding type of tribotest conditions. Similarly, the wear mechanism with various nano-sized particles, including $\mathrm{Cu}$ [47], $\mathrm{ZnAl}_{2} \mathrm{O}_{3}$ [2] and $\mathrm{ZrO}_{2}$ [51], has been reported by other researchers. They reported that this is because of the bearing ball effect of the nanoparticles which reduces the contact between the interacting surfaces.

Post-test chemical element analyses of worn tracks were conducted by using EDS in order to validate the hypothesis that nanoparticles contributed to the reduction in wear scars. The EDS spectra of worn tracks subject to nanocomposite coating and nano-oil showed the presence of $\mathrm{Al}$, as shown in Fig. 8b, c, respectively. The formation graphene protective tribofilm is evident from relatively higher (C) content element of $20.51 \%$ as shown in Fig. 8d. This is also in agreement with previous investigations about using nanoparticles as $\mathrm{Fe}, \mathrm{Cu}$, and $\mathrm{Co}$ as nano-additives in the lubricants [47]. The EDS spectra of the worn track, testing with pure nickel and pure oil (without nanoparticles) are also shown in Fig. 8a for comparison purpose.

\section{Conclusions}

Experimental results showed that the use of $\mathrm{Al}_{2} \mathrm{O}_{3}$ nanoparticles and graphene in the lubricating oil and nanoalumina reinforcement in composite coating can considerably reduce the wear and friction. In comparison, the addition of $\mathrm{Al}_{2} \mathrm{O}_{3}$ nanoparticles in the lubricant can provide the best tribological performance than $\mathrm{Ni}-\mathrm{Al}_{2} \mathrm{O}_{3}$ and using graphene as an additive in the lubricating oils. Also, the use of nanoparticle as an additive in lubricating oil is relatively cost-effective approach and a simple process, whereas the reinforcement of nanoparticles into the composite coating by electrodeposition technique is a complicated method involving a wide range of parameters to be controlled. Posttest surface analyses of worn tracks reveal that nano-enhanced lubricants and composite coatings display smoother surfaces and free of coating delamination, while pure nickel coatings which have been sliding against steel ball subjected to conventional oil presented severe surface deformation.

Moreover, during the EDS elemental surface analysis, the presence of $\mathrm{Al}_{2} \mathrm{O}_{3}$ hard nanoparticles and graphene within the worn track areas has confirmed the formation of, respectively, protective tribofilm.

\section{References}

[1] S. Shahnazar, S. Bagheri, S.B.A. Hamid, Int. J. Hydrogen Energy 41, 3153 (2016)

[2] X. Song, S. Zheng, J. Zhang, W. Li, Q. Chen, B. Cao, Mater. Res. Bull. 47, 4305 (2012)

[3] Z.J. Zhang, D. Simionesie, C. Schaschke, Lubricants 2, 44 (2014)

[4] B.S. Zhang, B.S. Xu, Y. Xu, F. Gao, P.J. Shi, Y.X. Wu, Tribol. Int. 4, 878 (2011)

[5] A. Guerrero-Martínez, J. Pérez-Juste, L.M. Liz-Marzán, Adv. Mater. 22, 1182 (2010)

[6] H.Y. Chu, W.C. Hsu, J.F. Lin, Wear 268, 960 (2010)

[7] Y. Wu, W. Tsui, T. Liu, Wear 262, 819 (2007)

[8] L. Rapoport, M. Lvovsky, I. Lapsker, W. Leshchinsky, Y. Volovik, Y. Feldman, R. Tenne, Wear 249, 149 (2001)

[9] L. Rapoport, Y. Feldman, M. Homyonfer, H. Cohen, J. Sloan, J. Hutchison, R. Tenne, Wear 225, 975 (1999)

[10] C. Lee, Tribol. Int. 55, 7 (2012)

[11] C. Lee, Tribol. Trans. 55, 640 (2012)

[12] R.S. Bajwa, Z. Khan, V. Bakolas, W. Braun, J. Adhes. Sci. Technol. 30, 653 (2016)

[13] T. Borkar, S.P. Harimkar, Surf. Coat. Technol. 205, 4124 (2011)

[14] K. Dass, S. Chauhan, B. Gaur, Tribol. Trans. 57, 157 (2014)

[15] R.S. Bajwa, Z. Khan, V. Bakolas, W. Braun, Acta Metall. Sin. (Engl. Lett.) 1, 8 (2016)

[16] S. Lajevardi, T. Shahrabi, Appl. Surf. Sci. 256, 6775 (2010)

[17] I.U. Haq, K. Akhtar, T.I. Khan, A. Ali Shah, Surf. Coat. Technol. 235, 691 (2013)

[18] Y.J. Xue, H.B. Liu, M.M. Lan, J.S. Li, H. Li, Surf. Coat. Technol. 204, 3539 (2010)

[19] E. Rudnik, L. Burzyńska, Ł. Dolasiński, M. Misiak, Appl. Surf. Sci. 256, 7414 (2010) 
[20] A.K. Pradhan, S. Das, Tribol. Trans. 57, 46 (2014)

[21] M. Surender, B. Basu, R. Balasubramaniam, Tribol. Int. 37, 743 (2004)

[22] H. Gül, F. Kılıç, M. Uysal, S. Aslan, A. Alp, H. Akbulut, Appl. Surf. Sci. 258, 4260 (2012)

[23] E. Beltowska-Lehman, P. Indyka, A. Bigos, M. Szczerba, M. Kot, Mater. Des. 80, 1 (2015)

[24] D. Berman, A. Erdemir, A.V. Sumant, Mater. Today 17, 31 (2014)

[25] J. Lin, L. Wang, G. Chen, Tribol. Lett. 41, 209 (2011)

[26] C.G. Lee, Y.J. Hwang, Y.M. Choi, J.K. Lee, C. Choi, J.M. Oh, Int. J. Precis. Eng. Manuf. 10, 85 (2009)

[27] Q. Zhou, C.L. He, Q.K. Cai, Adv. Mater. Res. 79, 631 (2009)

[28] M.H. Nazir, Z.A. Khan, A. Saeed, K. Stokes, Eng. Fail. Anal. 63, 43 (2016)

[29] A. Saeed, Z.A. Khan, M.H. Nazir, Sustainability 7, 16451 (2015)

[30] M. Nazir, Z. Khan, A. Saeed, K. Stoke, Corrosion 72, 500 (2016)

[31] M. Nazir, Z.A. Khan, K. Stokes, J. Adhes. Sci. Technol. 29, 1415 (2015)

[32] M. Nazir, Z. Khan, K. Stokes, J. Adhes. Sci. Technol. 29, 392 (2015)

[33] C. Ramesh, H. Adarsha, S. Pramod, Z. Khan, Mater. Des. 50, 597 (2013)

[34] A. Saeed, Z.A. Khan, M. Hadfield, S. Davies, Tribol. Trans. 56, 637 (2013)

[35] A. Saeed, E.L. Montgomery, Z.A. Khan, Mater. Perform. Charact. 2, 30 (2013)
[36] A. Saeed, Z. Khan, M. Clark, M. Nel, R. Smith, Insight NonDestr. Test. Cond. Monit. 53, 382 (2011)

[37] B. Karunamurthy, M. Hadfield, C. Vieillard, G. Morales-Espejel, Z. Khan, Ceram. Int. 36, 1373 (2010)

[38] Z.A. Khan, M. Hadfield, Mater. Des. 28, 2688 (2007)

[39] Z.A. Khan, M. Hadfield, S. Tobe, Y. Wang, Ceram. Int. 32, 751 (2006)

[40] Z.A. Khan, M. Hadfield, S. Tobe, Y. Wang, Mater. Sci. Eng., A 404, 221 (2005)

[41] Z.A. Khan, M. Hadfield, Y. Wang, Mater. Des. 26, 680 (2005)

[42] A. Jung, H. Natter, R. Hempelmann, E. Lach, J. Mater. Sci. 44, 2725 (2009)

[43] D. Thiemig, A. Bund, Appl. Surf. Sci. 255, 4164 (2009)

[44] J. Calderón, J. Henao, M. Gómez, Electron. Acta 124, 190 (2014)

[45] D. Thiemig, A. Bund, Surf. Coat. Technol. 202, 2976 (2008)

[46] X. Kang, B. Wang, L. Zhu, H. Zhu, Wear 265, 150 (2008)

[47] J. Padgurskas, R. Rukuiza, I. Prosyčevas, R. Kreivaitis, Tribol. Int. 60, 224 (2013)

[48] Y. Choi, C. Lee, Y. Hwang, M. Park, J. Lee, C. Choi, M. Jung, Curr. Appl. Phys. 9, e124 (2009)

[49] A.H. Battez, R. González, J. Viesca, J. Fernández, J.D. Fernández, A. Machado, R. Chou, J. Riba, Wear 265, 422 (2008)

[50] A.H. Battez, J. Viesca, R. González, D. Blanco, E. Asedegbega, A. Osorio, Wear 268, 325 (2010)

[51] W. Li, S. Zheng, B. Cao, S. Ma, J. Nanopart. Res. 13, 2129 (2011) 